ger of cystic degeneration, which takes away the hope of total disappearance by involution. There is also danger of the occurrence of septic infection with suppurative and gangrenous processes threatening the life of the patient. Growths springing from the cervical portion and extending between the layers of the broad ligaments occasion early and severe symptoms from pressure upon adjacent pelvic viscera. Submucous growths have a special danger from the hemorrhages which they induce. Sarcomatous degeneration of fibromyomata has been reported in a number of instances. It must be acknowledged that the prognosis of a growing fibroid is always a serious one. Such a growth is liable to cause death through the exhaustion consequent upon renal, cardiac or digestive disturbances; through the prolonged anemia or finally through septic or malignant changes in the tumor itself. In a large proportion of cases in which life is not destroyed the presence of these growths very greatly restricts the usefulness of the patient, prevents her from gaining a livelihood and entails upon her a prolonged condition of invalidism.

In view of these facts as stated above and in view of the less mortality which follows hysterectomy in the hands of competent operators, I believe the operation should be performed much more frequently than has been recommended by many surgeons. At the last International Medical Congress, Martin of Berlin affirmed that the total extirpation of the uterus would soon be accepted as one of the principal operations for the surgical treatment of uterine fibromata. Martin's series of twenty-six cases presented only one death - a mortality of 3.8 per cent.; Ott, twenty-four cases with one death; Bantock, twenty-three cases with one death; Carle, twenty cases with one death; Zweifel, ninety-three cases with three deaths; Leopold reports twenty cases with no death, and mentions Brennecke's report of nineteen cases with no death, making in all 225 cases with six deaths-a mortality of 2.6 per cent In Europe, five years ago, the mortality shown by the same class of operators was 25 per cent., while now they show a mortality of less than 8 per cent. In the United States, where the tendency is toward the operation of complete hysterectomy, in 281 united cases, three years ugo, there were but 22 deaths-a mortality of but 7.8 per cent. I have no doubt that the mortality is considerably less at the present time than it was three years ago. If this paper shall be the means of calling out a free discussion of this important subject, and shall cause to be put on record other cases of a similar nature I shall feel amply repaid for the labor in preparing it.

\section{GYNECOLOGY IN BERLIN.}

A. MACKENRODT.

BY JOSEPH RILUS EASTMAN, M.D. INDIANA POLIS. IND.

A. Mackenrodt is especially notable for his originalness. As a younger member of the Berlin Gynecological Society, he shies his castor with unaccustomed aggression before his seniors in age and rank, and is therefore unpopular. It was Mackenrodt (Dührrsen to the contrary notwithstanding) who introduced the ill-fated vaginal fixation for uterine retrodisplacements. $\mathrm{He}$ is the only continental exponent of igniextirpation for carcinoma uteri and of bloodless enucleation of the uterus for intractable postclimacteric inflammations and smaller fibromata. Under the im. pulse of the condemning reports of Paul Strassmann and others who had confined women with vaginally fixed uteri, "Mackenrodt's operation," after a short life, was relegated, as is well known, to comparative obscurity. Dührrsen still defends it qualifiedly, and the writer has seen A. Martin make the operation repeatedly and recently, but Martin places the uppermost of the three sutures not higher than a point four and one-half centimeters below the vertex of the fundus uteri. Mackenrodt himself having been driven to sectio Cæsaria after vaginal fixation in plural instances, forsook the method, convinced of its unfitness by the testimony of his own experience.

In its stead he is developing a new operation, a vesico-fixatio, by which it is sought to fix the fundus of the uterus over the fundus of the bladder by means of a flap of the latter's peritoneum. He shows by charts and frozen sections that the proversio-flexio so secured and maintained corresponds closely to the normal anatomic position. Two women operated on by this method have borne sound children at term. The technique is as follows: With the patient in the back posture, the anterior lip of the portio is seized with a double tenaculum and drawn forward and downward as for anterior colporrhaphy. A split is then made through the anterior vaginal mucosa, extending in the median sagittal line, from the anterior utero-vaginal junction forward, half way toward the meatus urethræ. The septum vesico-uterinum and the vesico-uterine reflection of peritoneum are successively exposed and divided transversely. The tenaculum in the anterior lip is then replaced by a guy ligature, and the portio is pushed upward and backward to force the vagina conversely forward and downward. To bring the fundus into the vaginal incision double tenaculæ are used. With these one "climbs" upward along the anterior uterine surface, applying each higher than the last, until the vesical peritoneum, which has been peeled loose as high up as possible, may be laid flap-like over the fundus uteri and stitched fast. The peritoneum is drawn as a curtain between the operator and the fundus, the stitches being applied into the latter "through the curtain." The fundus is now released and the anterior vesical flap of the septum vesico-uterinum is sutured into the muscular uterus as high up as the internal os, a centimeter higher than its anatomic attachment, to the end that the fundus may be held more securely forward. An adhesive peritonitis is expected to provide permanent fixation.

In a communication to the Centralblatt für Gynecologie, 1895, No. 6, Mackenrodt took the position that adequate use of the glowing cautery offers the only hope for improvement in the statistics of lasting results after extirpation for carcinoma uteri. He recommended that the entire operation be made with the cautery, that the entire wound surface be charred, the goal sought being prevention of inoculation infection. $\mathrm{He}$ maintained that even in that instant when the tissues are divided, the wound surface must be protected against the invasion of cancer germs, and that such protection is only possible when all dissecting is done with the Paquelin. "Methods in which the cautery supplements the knife, ligature or clamp are illusory." In an experience of thirty igni-extirpations, Mackenrodt claims not to have had a single recurrence, the post operationem period of observation varying between one and two years; nor was any patient lost from shock. 
Having found by experiment and observation ${ }^{1}$ that even the largest blood vessels may be safely sealed by the Paquelin in that instant when they are severed by the same, Mackenrodt went a step farther and said "all hemorrhage must be checked by the charring cautery," and that clamps used during the operation to protect the surrounding tissue may be removed directly the operation is finished. The possibility of closing the uterina and spermatica he adds, however, is only present after a provisory application of suitable clamps (wing-jawed like the Langenbeck hemorrhoid clamp, shovel-shaped and curved on the flat), with which the stump to be treated may be emptied of blood and charred, without injury to the urethra, rectum or bladder.

The vaginal igni-extirpation after Mackenrodt is made as follows: After thorough cleansing of the
vagina, curettement and cauterization of the exposed carcinomatous foci, the field of operation is disinfected with alcohol and sublimate. If the vulva is small a lateral incision is made with the cautery into the perineum. The portio is then seized with strong double tenacula, drawn downward and forward, and with the Paquelin the posterior vaginal wall is separated from the collum, and the cavum Douglasii opened. The vaginal wall is next burned off laterally, and lastly anteriorly from the uterus.

The connective tissue between the bladder and the uterus and ligamenta lata is now put upon the stretch by the thumb of the left hand pressing against the anterior vaginal wall, In dividing these connections the Paquelin is drawn from left to right in repeated strokes, the tissues giving way in the direction of least resistance, exposing the anterior aspect of the uterus and broad ligaments. The shovel-shaped clamps are now applied to the broad ligaments, their concavity toward the uterus. The stumps on each side are successively burned through and charred to the surface of the clamps. The clamps are removed and the remaining connections between the bladder and uterus are divided in the manner described above. The peritoneal cavity having been opened anteriorly, the left index finger is passed through the opening, over the crest of the right broad ligament, and a clamp is reintroduced and made to embrace the remaining peritoneal portion of the stump. The latter is then divided with the cautery. Lastly, the clamp is applied to the left ligamentum latum, the stump divided and the uterus removed. Iodoform gauze is placed in the peritoneal opening to prevent the decensus of intestines and the perineal incision is sutured up.

Mackenrodt is a warm advocate of Battey's colpotomia posterior. He practices the operation bimself and has done much to bring it into new favor. $\mathrm{He}$ prefers the posterior to the anterior vaginal section, because of the former's simplicity and safety of principle.

During the last few months he has removed all uteri demanding radical operation for other conditions than malignant neoplasms and large fibroids by enucleation. In the majority of cases he is able to accomplish this without the use of a single ligature. Occasionally, however, he ligates the ovarian artery. The technique is the simplest possible. He seizes the portio with a double tenaculum, and with a pair of short curved scissors makes an annularincision through

1 After castration of stallions, hemorrhage from the spermatic artery may be checked without ligature, by the application of a red hot
iron. the vaginal vault at the utero-vaginal junction. He proceeds upward, clipping with the scissors in the endopelvic fascia, until the uterus is freed.

Delaware and Vermont Streets.

\section{LEPROSY}

OVERCOME BY ISOLATION IN THE MIDDLE AGES.

\section{BY ALBERT S. ASHMEAD, M.D.} NEW YORK.

In the Middle Ages leprosy spread in every country of Europe and continued to spread until strenuous efforts were made to bring the diseased parts out of contact with the healthy community. In this no charitable regard was had to the victims of the scourge; the weal of the sane majority alone was considered. It is from this point of view that it behooves us also to judge the conduct of the church. The Order of Lazarus was founded and lazarettoes built in great numbers. The work and purpose of the order were to segregate and govern the afflicted and dangerous part of humanity. The thing was necessary, was an unavoidable consequence of the resolve of healthy mankind to remain so, and it was not so much charity as one might believe. The community wanted this work to be done, and who could do it but the church?

But, according to Dr. Ehlers, Secretary-General of the Berlin Lepra Conference, the church might have been spared these worries and these dangers, for isolation is not necessary, as these Middle Age people believed, who, through isolation, were fortunate enough finally to overcome the disease.

It is not certain that the growth of civilization since the Middle Ages has rendered the spread of leprosy impossible. We cheerfully admit that it can not overwhelm people who are clean in their habits, well separated in their families, careful of their bedding, living in sufficient remoteness from the inferior animals, etc., as it did our ancestors of the Middle Ages, whose life was so very different. Yet some danger still exists, and the spread of leprosy in various parts of Europe, and in parts which I venture to say are cleaner than the leprosy centers of Norway and Iceland, proves that the disease has not lost, under any circumstances, its vital stamina; it seems to stir itself with remarkable vigor, and to be able to take advantage of any elbow room left to it.

If enforced isolation and a permanent committee of official delegates do not come out of the Congress of Berlin-and Dr. Ehlers does not want them tothat Congress will have been held for nothing, or at loast only ad majorem Ehlerii gloriam.

\section{SURGERY ONE HUNDRED YEARS AGO.} AN HISTORICAL STUDY BY DR. GEORGE FISCHER.

DEDICATED TO THE GERMAN SURGICAL ASSOCIATION.

TRANSLATED FOR THE JOURNAL OF THE AMERICAN MEDICAL ABSOCIATION BY CARL H. VON KLEIN, A.M., M.D.

(Continued from page 631.) XIII.-GERMAN MEDICINE.

Albert von Haller (1708-1777) shone above all others. Born for science, at the age of 8 years he applied himself to Greek and Hebrew dictionaries, outlined a Chaldean grammar and collected the biographies of several thousand celebrated men. While a 